\title{
Dynamics of the Oso-Steelhead landslide from broadband seismic analysis
}

\author{
C. Hibert, C. P. Stark, and G. Ekström \\ Lamont-Doherty Earth Observatory, Columbia University, Palisades, NY, USA \\ Correspondence to: C. Hibert (hibert@1deo.columbia.edu)
}

Received: 12 November 2014 - Published in Nat. Hazards Earth Syst. Sci. Discuss.: 5 December 2014

Revised: 14 May 2015 - Accepted: 21 May 2015 - Published: 17 June 2015

\begin{abstract}
We carry out a combined analysis of the shortand long-period seismic signals generated by the devastating Oso-Steelhead landslide that occurred on 22 March 2014. The seismic records show that the Oso-Steelhead landslide was not a single slope failure, but a succession of multiple failures distinguished by two major collapses that occurred approximately $3 \mathrm{~min}$ apart. The first generated long-period surface waves that were recorded at several proximal stations. We invert these long-period signals for the forces acting at the source, and obtain estimates of the first failure runout and kinematics, as well as its mass after calibration against the mass-centre displacement estimated from remotesensing imagery. Short-period analysis of both events suggests that the source dynamics of the second event is more complex than the first. No distinct long-period surface waves were recorded for the second failure, which prevents inversion for its source parameters. However, by comparing the seismic energy of the short-period waves generated by both events we are able to estimate the volume of the second. Our analysis suggests that the volume of the second failure is about $15-30 \%$ of the total landslide volume, giving a total volume mobilized by the two events between $7 \times 10^{6}$ and $10 \times 10^{6} \mathrm{~m}^{3}$, in agreement with estimates from ground observations and lidar mapping.
\end{abstract}

\section{Introduction}

On 22 March 2014, a catastrophic landslide occurred $6.4 \mathrm{~km}$ east of Oso (Washington, USA), in the North Fork Stillaguamish River valley, destroying the neighbourhood known as "Steelhead Haven" and causing 43 fatalities (Keaton et al., 2014; Iverson et al., 2015). The failure oc- curred on a slope which had already been affected by at least six episodes of collapse since 1955. It was preceded by several days of heavy rainfall. The lithology of the North Fork Stillaguamish River valley consists of a surface unit formed by glacial-fluvial sediments, underneath which lies a sequence of glacial-lacustrine silts and clays (Dragovich et al., 2003; Keaton et al., 2014).

The block field constituting the bulk of the landslide travelled approximately $1.1 \mathrm{~km}$ and separated into two segments. The majority of the mobilized material accumulated in the western segment. The highly-liquefied distal debris flow travelled a maximum distance of approximately $1.4 \mathrm{~km}$ in the western segment and $1.6 \mathrm{~km}$ in the eastern segment (Keaton et al., 2014). Deposits of the landslide formed a dam on the north fork of the Stillaguamish river. Ground observations suggest a total volume of the deposits comprised between $7.3 \times 10^{6} \mathrm{~m}^{3}$ and $9.2 \times 10^{6} \mathrm{~m}^{3}$ (Iverson et al., 2015).

Reconstructing the failure sequence of a landslide mass is a challenging task, as direct observations of the mass movements are rare. In recent years, seismology has proven useful in this regard by offering a way to infer the dynamics of large mass movements (e.g., Brodsky et al., 2003; Favreau et al., 2010; Schneider et al., 2010; Moretti et al., 2012; Yamada et al., 2013; Allstadt, 2013) and estimate important properties such as the mobilized mass (Ekström and Stark, 2013). Additional analysis of the short-period waves provides an extra constraint on source mechanisms and a more complete understanding of the dynamics of slope failures (e.g., Suriñach et al., 2005; Deparis et al., 2008; Vilajosana et al., 2008; Dammeier et al., 2011; Hibert et al., 2011, 2014).

In this study we present a joint interpretation of the longperiod force history of the Oso-Steelhead landslide and the associated short-period seismic signals. Our study builds on 


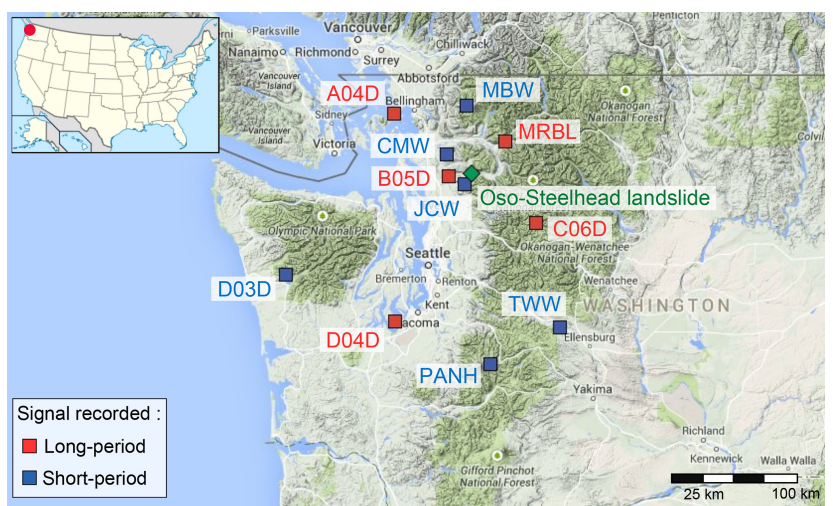

Figure 1. Map of seismic stations used in the investigation of the Oso-Steelhead landslides. Blue squares show stations with good short-period signals $(1-10 \mathrm{~Hz})$; red squares show stations with good long-period signals (40-150s). The stations belong to the Pacific Northwest Regional Seismic Network (CMW, JCW, MBW and TWW), the USArray Transportable Array (A04D, B05D, C06D, D03D and D04D) and the Cascade Chain Volcano Monitoring network $(\mathrm{PANH})$.

and extends the ground observations and results presented in the Geotechnical Extreme Events Reconnaissance report by Keaton et al. (2014). Our work also benefits from some of the results presented in the recent study of the landslide by Iverson et al. (2015). We note that our seismological analysis is different from that of Iverson et al. (2015), and that our results differ in important ways from those obtained in that study. We discuss these differences and their likely explanation in some detail in the Appendix.

We first present the seismic observations made on shortperiod and broadband stations, which indicate that two consecutive slope failures occurred. We then present the results of the inversion of the landslide force history (LFH) of the long-period signals generated by the first landslide, and provide an estimate of its mass, peak velocity and acceleration. Finally we compare the short-period seismic signals to the $\mathrm{LFH}$, which leads to an interpretation of the dynamics of the first landslide. We discuss, based on a comparison of the seismic records and with reference to the ground observations, possible source characteristics of the second event.

\section{Seismic observations}

The seismic waves generated by the Oso-Steelhead landslide were recorded by several short-period and broadband stations (Fig. 1). Two high-amplitude short-period signals were recorded on stations at distances ranging from 11.7 to $180 \mathrm{~km}$. The first seismic signal onset was recorded at 17:37:22 UTC on the closest short-period station (JCW) from the Pacific Northwest Regional Seismic Network (FDSN network code UW), at a distance of $11.7 \mathrm{~km}$. The short-period $(1-10 \mathrm{~Hz})$ seismic signal recorded at JCW has a duration of

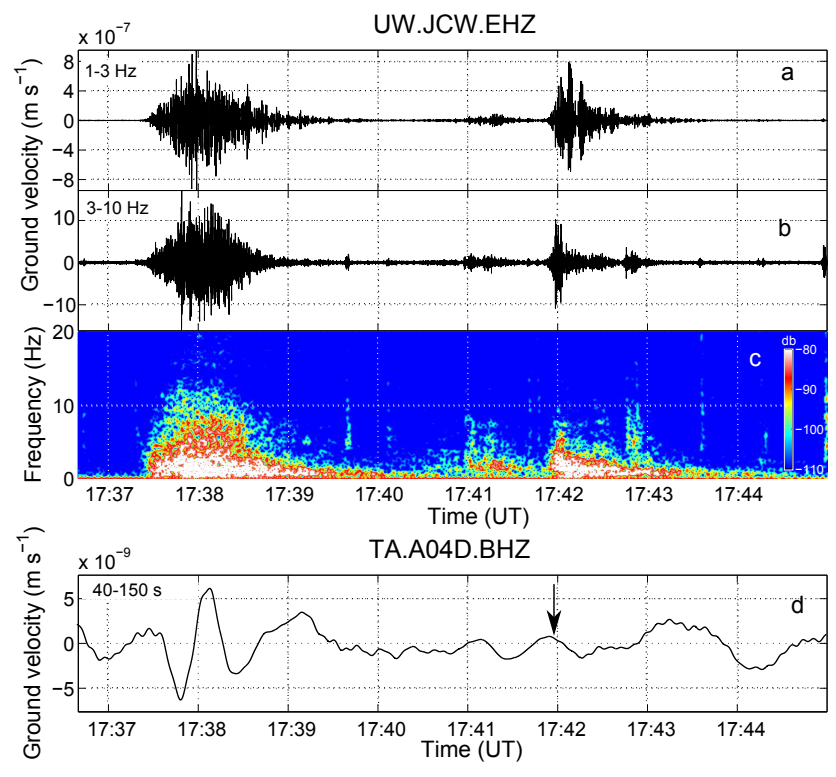

Figure 2. Seismic signals recorded at the short-period station JCW, located $11.7 \mathrm{~km}$ from the Oso-Steelhead landslide, filtered between (a) $1-3 \mathrm{~Hz}$ and (b) $3-10 \mathrm{~Hz}$. (c) Spectrogram of the seismic signal computed using fast-Fourier transform, with an $8 \mathrm{~s}$ moving window and a $90 \%$ overlap. (d) Long-period seismograms recorded at the station B05D and filtered between 40 and $150 \mathrm{~s}(0.0067-0.025 \mathrm{~Hz})$. The black arrow indicates the onset time of the short-period seismic signal generated by the second event.

approximately $100 \mathrm{~s}$, and exhibits all the known features of landslide-generated seismic signals: emergent onset, no distinct $\mathrm{P}$ and $\mathrm{S}$ waves and no clear peak amplitude visible in the higher-frequency bands (Fig. 2a and b) (Suriñach et al., 2005; Deparis et al., 2008; Dammeier et al., 2011; Hibert et al., 2011). Spectral analysis of the seismic signal recorded at JCW shows persistent high energy between 1 and $10 \mathrm{~Hz}$ (Fig. 2c), remaining high for approximately $1 \mathrm{~min}$ before a gradual decay.

A second event was recorded at 17:41:53 at JCW. Its signal has a more impulsive onset than that of the first event and a shorter duration of $60 \mathrm{~s}$. It exhibits several consecutive amplitude peaks in the $1-3 \mathrm{~Hz}$ frequency band (Fig. 2a). The onset of the seismic signal of the second event is marked by a high-amplitude burst of energy in the $3-10 \mathrm{~Hz}$ band (Fig. 2b). A second burst of energy in this frequency band is observed at the end of the signal (Fig. $2 b$ and c). The two peaks following the onset and observed in the $1-3 \mathrm{~Hz}$ band do not appear in the $3-10 \mathrm{~Hz}$ frequency band (Fig. 3). On the closer station (JCW), several other weak but distinct short-period signals were recorded (e.g., at 17:43:30 - Fig. 3b) that were possibly generated by residual collapses in the hours following as a result of local destabilization caused by the two main events.

Long-period surface waves (period ranging from $T=40 \mathrm{~s}$ to $T=150 \mathrm{~s}$, corresponding to a frequency range of 0.0250 to $0.0067 \mathrm{~Hz}$ ) were also detected for the first event (Fig. 2d) 

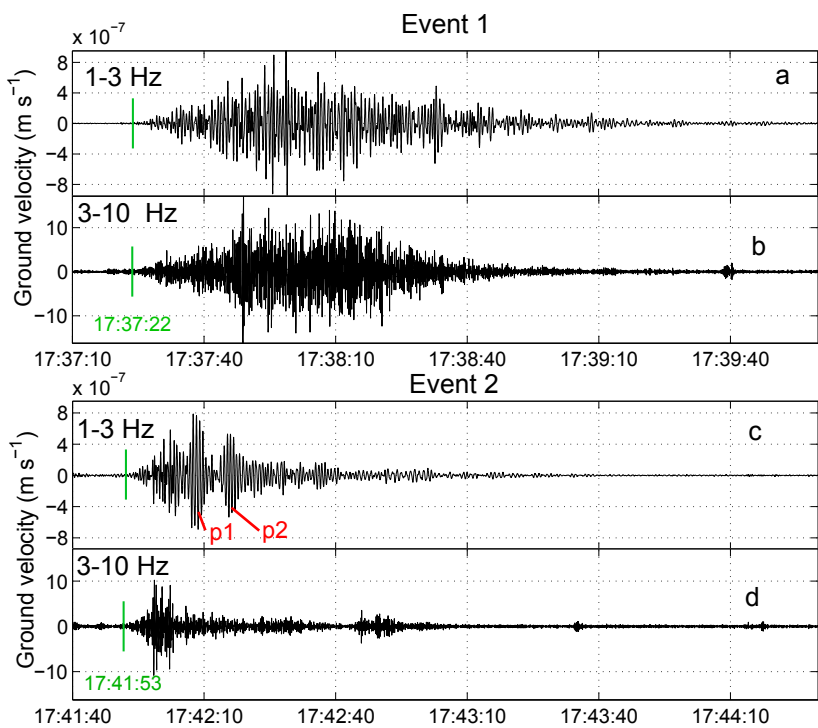

Figure 3. Seismic signals in detail for (a) and (b) event 1, and for (c) and (d) event 2 at station JCW, filtered between 1-3 Hz and $3-$ $10 \mathrm{~Hz}$, respectively. The onset time for both signals is indicated by the green line. Labels p1 and p2 indicate the two amplitude peaks observed only in the seismic signal of the second event filtered in the $1-3 \mathrm{~Hz}$ frequency band.

at five broadband stations (four from the USArray Transportable Array), with distances from the landslide ranging from 18.3 to $140.8 \mathrm{~km}$. No distinct long-period seismic signal was observed for the second event (Fig. 2d). Several differences between the seismic signals of the two events are therefore identified: (1) the seismic signal of the second event has a more impulsive onset than the first (Fig. 2a and b); (2) several distinct amplitude peaks are observed in the signal of the second event filtered in the $1-3 \mathrm{~Hz}$ frequency and not for the first event (Fig. 2a); (3) the seismic signal of the second event has less energy in the frequency band above $5 \mathrm{~Hz}$ compared to the first (Fig. 2c); (4) a long-period signal was generated by the first event, and absent for the second. These observations suggest differences in the dominant source characteristics.

\section{Force history of the first Oso-Steelhead landslide}

The acceleration and deceleration of the bulk mass during the landslide cause a loading and unloading of the slope that generates long-period seismic waves. The forces acting on the slide mass that bring about this loading-unloading cycle are gravity, basal friction, and centripetal forces, and each of these has a reactive counterpart acting on the solid earth in the opposite direction across the slide contact area (e.g., Kanamori and Given, 1982; Fukao, 1995; Brodsky et al., 2003; Ekström and Stark, 2013). The landslide therefore exerts a force $\mathbf{F}$ on the solid Earth that is the vector opposite of the force $\mathbf{F}_{\mathrm{S}}$, equivalent to the bulk momentum change of the slide

$\mathbf{F}[\boldsymbol{x}, t]=-\mathbf{F}_{\mathrm{S}}=-\frac{\mathrm{d}(m \boldsymbol{v})}{\mathrm{d} t}[\boldsymbol{x}, t]$

with $m$ the mass of landslide, $\boldsymbol{v}$ the velocity of the centreof-mass at the position of the centre of mass $\boldsymbol{x}$ and at the time $t$. The time-varying forces acting on the slope during the loading-unloading cycle can be retrieved by inversion of long-period seismic waves, and thereby provide a force history from which information on the dynamics of the landslide can be inferred.

We use the inversion method developed by Ekström and Stark (2013) to determine the landslide force history (LFH) of the Oso-Steelhead landslide from the long-period waveforms recorded at five broadband stations. The method is based on the approximation that, when considering the longperiod signals, the landslide seismic source can be described as a time-varying, 3D force vector acting at a fixed point (Kanamori and Given, 1982; Fukao, 1995; Brodsky et al., 2003; Ekström and Stark, 2013; Allstadt, 2013). This assumption is justified to the extent that the spatial scale of the slide is small compared to the wavelength of the seismic waves and to the distances to the recording seismic stations. Hence we restrict our analysis to signals with periods comprised between 40 and $150 \mathrm{~s}$.

The time history of each component (north, east, vertical) was parameterized using a sequence of isosceles triangles overlapping by their half-duration. We solved for the amplitudes of the triangles that define the time histories of each component of the force by minimizing, in a least-squares sense, the misfit between observed and corresponding synthetic seismograms (Fig. 4a). Synthetic seismograms were calculated by summation of Earth's elastic normal modes with corrections for laterally heterogeneous crust and mantle (Ekström, 2011). The time history of each force component was constrained to integrate to zero to satisfy the condition that the sliding mass must be at rest before and after the landslide. We tested a wide range of different source models by adjusting the number of and width of triangular subsources, as well as by the selection of seismograms to include in the inversion. The preferred model was obtained using a parameterization in terms of 8 triangles with a half duration of $10 \mathrm{~s}$. The main characteristics of the derived Landslide Force History are robust with respect to data selection and source parameterization.

The maximum of the inverted forces is $1.3 \times 10^{10} \mathrm{~N}$ and the duration of sliding is approximately $90 \mathrm{~s} \mathrm{(Fig.} \mathrm{4b).} \mathrm{The}$ time-varying displacement $\mathbf{D}[t]$ of the centre of mass is estimated from double integration of the forces

$\mathbf{D}[t]=-\frac{1}{m} \int_{0}^{t} \int_{0} \mathbf{F}[\tau] \mathrm{d} \tau$. 


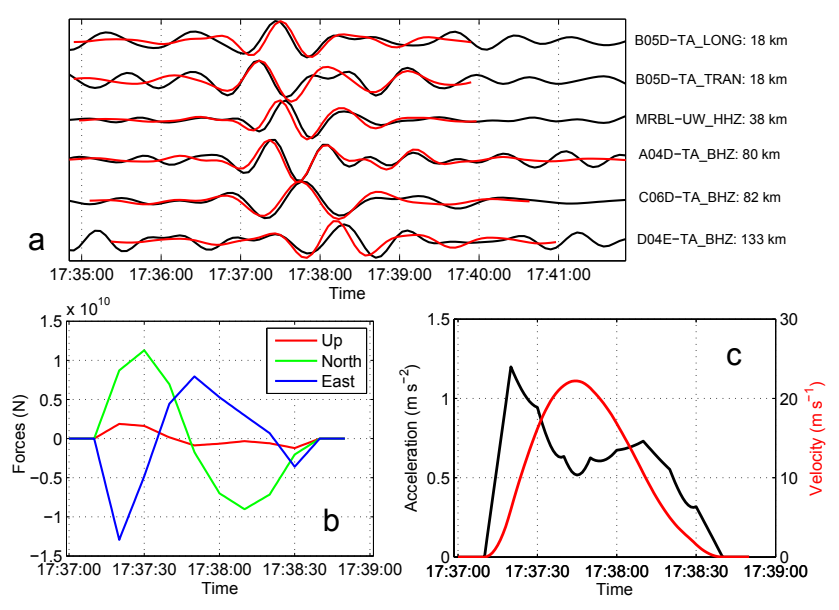

Figure 4. (a) Observed (black) and synthetic (red) long-period seismograms filtered between 40 and $150 \mathrm{~s}$ for the first Oso-Steelhead landslide. The station name, component and distance to the landslide are given to the right of each trace. (b) Landslide force histories inverted for the first Oso-Steelhead landslide. (c) Temporal evolution of the acceleration and the velocity of the centre of mass inferred from the integration of the inverted forces.

The trajectory is scaled to fit ground observations by adjusting the mass $m$ in Eq. (2), thus also providing an estimate of the mass. The inverted trajectory that best fits the geometry of the source area and of the deposits was obtained by using a mass of $1.5 \times 10^{10} \mathrm{~kg}$, and it shows an initial centreof-mass acceleration to the south-east and then a propagation to the south (Fig. 5). The curvature of the trajectory follows the shape of the maximum accumulation area well. We infer a run-out distance of $800 \mathrm{~m}$. Assuming a density of the deposits of $2000-2500 \mathrm{~kg} \mathrm{~m}^{-3}$, the inferred volume ranges from $6.0 \times 10^{6}$ to $7.5 \times 10^{6} \mathrm{~m}^{3}$. This is similar to, but smaller than, the value obtained by an analysis of the total landslide deposits (Keaton et al., 2014).

We infer kinematic parameters from the integration of the inverted forces. The maximum bulk speed reached by the centre of mass of the landslide was $19.4 \mathrm{~m} \mathrm{~s}^{-1}$ and the maximum acceleration was $1.0 \mathrm{~m} \mathrm{~s}^{-2}$ (Fig. 4c). The maximum speed, and the associated momentum and kinetic energy, are reached after $35 \mathrm{~s}$ after a displacement of approximately $400 \mathrm{~m}$ (Fig. 6), which corresponds to the moment when the centre of mass reached the break between the slope and the valley (Fig. 5). After this time the scalar product of the opposing force $\mathbf{F}$ and the normalized momentum $\widehat{\boldsymbol{p}}$ becomes negative (red curve on Fig. 5a), which indicates that the centre of mass starts to decelerate along the path. The total potential energy lost during the slide computed from the drop in height inferred from the LFH is about $1.6 \times 10^{13} \mathrm{~J}$. It is almost 6 times the maximum kinetic energy calculated from the centre-of-mass velocity, estimated at $2.8 \times 10^{12} \mathrm{~J}$ (Fig. $6 \mathrm{a}$ and $b$ ).

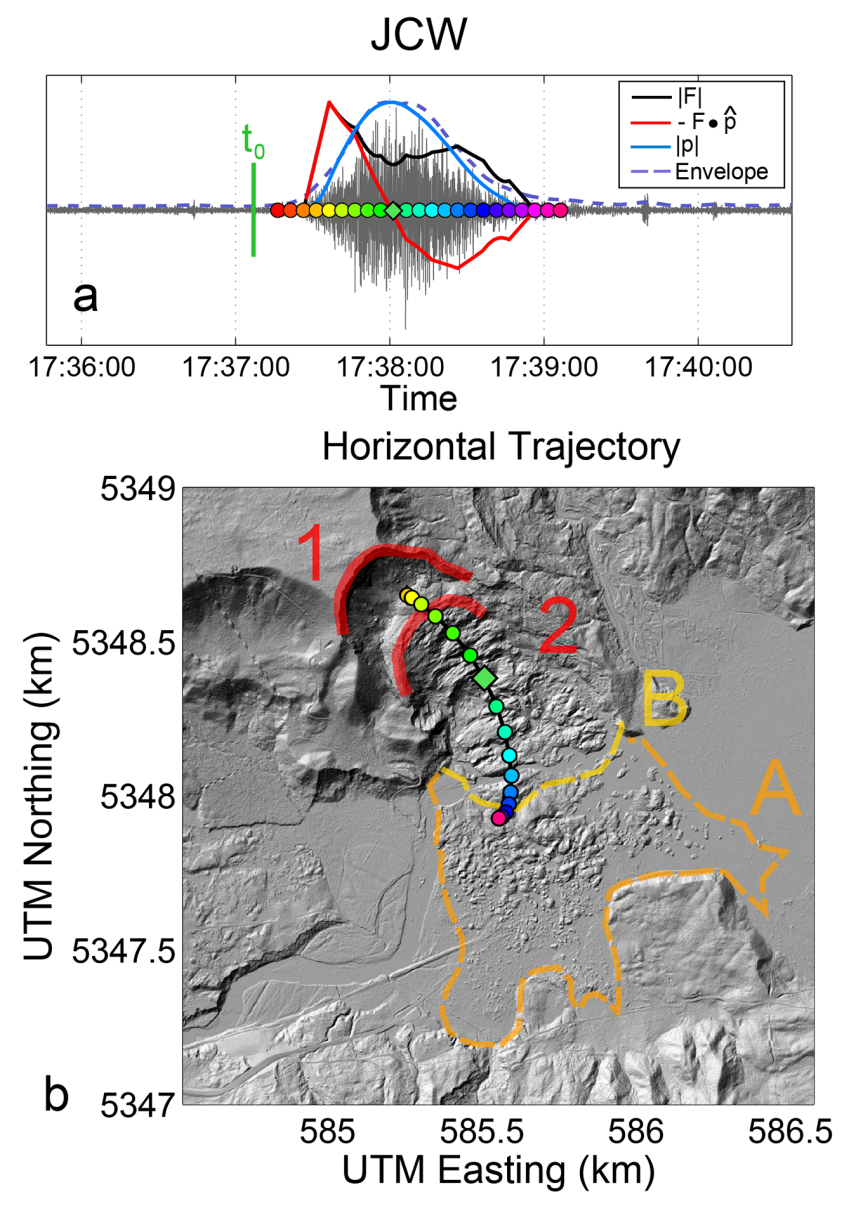

Figure 5. (a) Short-period seismogram at station JCW filtered between 3 and $10 \mathrm{~Hz}$ together with the modulus of the inverted forces (black curve), the scalar product of the opposing force $\mathbf{F}$ and the normalized momentum $\widehat{\boldsymbol{p}}$ (red curve), the modulus of the inverted momentum (blue curve) and the smoothed envelope. Time $t_{0}$ indicates the origin start time of the LFH, before shifting it by the travel time of the seismic waves. (b) Inferred centre-of-mass trajectory for the first landslide. Coloured dots indicates the time at which the centre of mass occupied the corresponding position along the inferred trajectory. The yellow and orange-dashed contours labelled A and $\mathrm{B}$ indicate the extent of the first and second landslides deposits respectively, identified by Keaton et al. (2014). The red lines labelled 1 and 2 indicate two possible locations for the source area of the second landslide.

\section{Discussion}

\subsection{Dynamics of the first event from comparison of the LFH and short-period data}

The combined analysis of short-period seismic data with the dynamics inferred from long-period waves provides important information on large landslide motion (Schneider et al., 2010; Yamada et al., 2013; Allstadt, 2013; Hibert et al., 2014). While the long-period waves and the force-history (LFH) inversion provide insight into the temporal evolution 

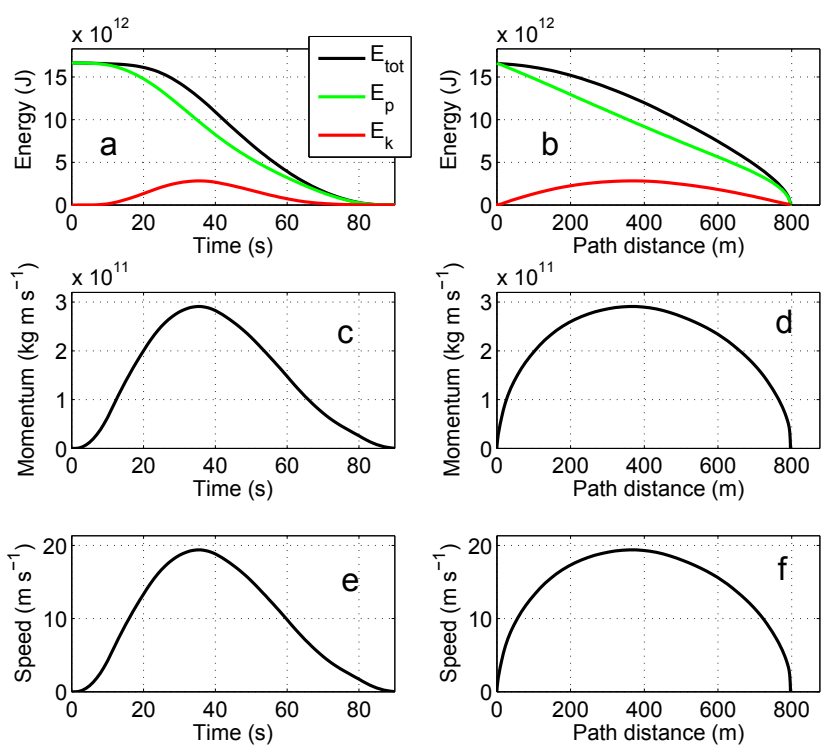

Figure 6. Total energy (black), potential energy (green) and kinetic energy (red) as (a) a function of the time and (b) a function of the travelled distance. Momentum of the centre-of-mass as (c) a function of the time and (d) a function of travelled distance. Speed of the centre-of-mass as (e) a function of the time and (f) a function of the travelled distance.

of the bulk momentum of the whole landslide mass, the shortperiod waves reflect spatially complex momentum exchanges across the basal slide area at shorter length scales. Hence short-period signals are sensitive to far more variables, including small-scale relief and topographic obstacles along the runout path, variability in basal friction and mobility of the granular material within the sliding mass. Strong impulsive bursts of energy in the short-period signals can sometimes be tied to the fall of individual blocks (Huang, 2007) or to the impact of debris after a free-falling phase (Deparis et al., 2008; Dammeier et al., 2011; Hibert et al., 2011).

In order to compare the LFH with the short-period seismic signals, we first computed the travel time of the signal with respect to the origin time given by the LFH inversion. An average propagation velocity can be estimated from comparison of the arrival times recorded at stations JCW and CMW, for which good quality time-picks of the signal onset were possible. We find an average velocity of $\sim 1.1 \mathrm{~km} \mathrm{~s}^{-1}$. Using this velocity, a shift of $10 \mathrm{~s}$ is applied to the LFH to align it with the short-period seismic signal recorded at station JCW. The interpretation that follows is not sensitive to small variations in this assumed propagation velocity.

As Fig. 5 shows, the initial acceleration of the landslide generated very weak short-period seismic waves. Once peak acceleration of the centre of mass was reached, a lowamplitude short-period signal emerged from the noise. This delay suggests fragmentation of the initially intact mass while it was already accelerating on the slope (Allstadt, 2013; Hibert et al., 2014). At that point, the magnitude of accel- eration along the trajectory started to decrease. The highest amplitudes of the short-period seismic signal occurred at the moment deceleration began. During the whole deceleration phase (inferred from the LFH), the short-period seismic signal amplitude decreased monotonically and passed below the noise level at roughly the same time that the centre of mass came to a halt.

\subsection{Estimating the dynamics and size of the second event from short-period signals}

The seismic signals of the second event are more difficult to interpret. The two amplitude peaks observed (following band-pass filtering at $1-3 \mathrm{~Hz}$; indicated by $\mathrm{p} 1$ and $\mathrm{p} 2$ on Fig. 3) at approximately 15 and $25 \mathrm{~s}$ after the signal onset of the second event are possibly related to the impacts of large chunks of debris with the terrain or with the earlier landslide surface after a free-fall or a very short-lived motion. A composite slope failure process is another possible explanation. These two amplitude peaks are not visible in the $3-10 \mathrm{~Hz}$ band. In a previous study (Hibert et al., 2014), we observed that seismic signals produced by the two major landslides during the Bingham Canyon open-pit mine collapse exhibited amplitude peaks that originated in the flowing mass hitting topographical barriers and that were stronger in the $1-3 \mathrm{~Hz}$ frequency band than in the $3-10 \mathrm{~Hz}$ band. This observation points to a potential higher sensitivity of the 1$3 \mathrm{~Hz}$ frequency band to topographical effects, and prompts the interpretation that the two peaks observed for the second Oso-Steelhead event might have been generated as sliding and flowing debris encountered topographic obstacles. A succession of multiple intricate breakaways and short phases of motion may also explain why no strong long-period waves were generated by the second event.

In the absence of significant long-period seismic waves records for the second event, we are not able to determine its mass and volume using the inversion method presented above. However, the lack of a long-period signal constrains the bulk momentum change of the second event to be much smaller than that of the first. The amplitude of the longperiod signal of the first event recorded at the closest station (B05D) is approximately 3 times higher than the noise amplitude. The amplitude of the long-period signal is roughly proportional to the force exerted by the landslide on the earth, and hence to the mass and the acceleration of the centre-ofmass of the landslide. If we assume the same peak acceleration for the centre-of-mass of both events (Ekström and Stark, 2013), the fact that the amplitude of the long-period seismic signal of the second event is lower than the noise level implies that the mass of the second landslide is at least 3 times lower than the mass of the first. Consequently, the upper bound for the second landslide mass is roughly $25 \%$ of the total mass mobilized. Note that this upper bound would increase if the centre-of-mass peak acceleration of the second landslide were smaller than the first. 
Earlier studies (Hibert et al., 2011; Dammeier et al., 2011) have shown that a rough estimate of landslide volume can be deduced from analysis of the seismic energy of the shortperiod waves, thought to be related to the potential energy released by vertical displacement of the landslide mass. It is important to note that the direct relationship between the seismic energy and the volume of granular flows established by Hibert et al. (2011) is dependent on the slope parameters. Therefore comparing the seismic energy of the short-period waves generated by two different landslides is only relevant when the geometry of the source is similar, and the dominant process at the origin of the short-period seismic wave is the flow of a granular mass. With the assumption that the two events of the Oso-Steelhead sequence roughly share the same source geometry and behave principally as granular flows, we computed and compared the energy of the seismic signal of the first and second landslides in the $3-10 \mathrm{~Hz}$ frequency band. This frequency band is close to that chosen for the events for which this seismic-energy approach has been developed (Hibert et al., 2011; Dammeier et al., 2011). Choosing to compare the seismic energy generated in the 3$10 \mathrm{~Hz}$ frequency band also has the advantage that it eliminates the two high-amplitude peaks that could otherwise unduly influence the computation of the seismic energy, as they are probably generated by other mechanisms than the simple flow of the granular mass. We found a seismic energy ratio between the first and second events of 6.5 at the JCW station. If the ratio of dissipated potential energies is the same as their seismic energy ratio, and if we assume (for the moment) the same run-out distances and the same average sliding angle for both events, the second slope collapse would have a mass approximately $13 \%$ of the total mobilized Oso landslide mass. However, ground observations (Keaton et al., 2014) and the measured duration of short-period seismic signals suggest that the run-out distance of the second event is shorter than the first, possibly by a factor of 2 or 3 , depending on where the source area of the second landslide is located.

Two possible locations for the source area of the second event can be assumed (Fig. 5b): (a) at the head scarp, or (b) from the collapsed structure resting at the top of the deposits of the first event. A shorter run-out distance with the same amount of potential energy dissipated would imply that the mass of the second event is bigger, assuming the same angle of sliding. For scenario (a), with a run-out distance half that of the first landslide, the second landslide would represent approximately $20 \%$ of the total collapsed mass. For scenario (b), with a run-out distance for the second landslide a third of the first, the mass of the second collapse would represent $30 \%$ of the total landslide mass. Given the uncertainty over which scenario is correct, we estimate the percentage of the debris mobilized by the second event at between 15 and $30 \%$ of the whole Oso landslide mass. This is in agreement with the ground observations (Keaton et al., 2014) and their volume estimate for the second major failure at around 15 to $50 \%$ of the total.

\section{Conclusions}

Our analysis of the seismic signals generated by the OsoSteelhead landslide provides information on its failure sequence together with estimates of key parameters of the landslide dynamics. Two separate events are identified from the seismic data recorded at proximal stations, confirming ground observations of two distinct and substantial slope failures (Keaton et al., 2014). Differences in the seismic features of each event point to variation in their source characteristics and therefore differences in the way runout took place in each case.

The seismic signal of the first event exhibits all the known features of those generated by landslides, with emergent onset, no distinct $\mathrm{P}$ and $\mathrm{S}$ waves and no clear high-amplitude peak in the higher frequency bands. The strong long-period surface waves indicate the mobilization and acceleration of a large landslide mass. Inversion of these long-period surfacewaves generates a "landslide-force history" or LFH. The bulk run-out trajectory inferred from this LFH is consistent with ground and remote-sensing observations. Through approximate scaling of the LFH trajectory against these observations, we estimate that the mass of the first landslide is about $1.5 \times 10^{10} \mathrm{~kg}$, corresponding to a volume in the range $6.0 \times 10^{6}$ to $7.5 \times 10^{6} \mathrm{~m}^{3}$. The peak centre-of-mass velocity and acceleration inferred from the LFH inversion are $19.4 \mathrm{~m} \mathrm{~s}^{-1}$ and $1.0 \mathrm{~m} \mathrm{~s}^{-2}$, respectively.

The seismic signal of the second event is more impulsive, shows several amplitude peaks, and has little energy at long periods, which makes LFH inversion impossible. While these observations are difficult to interpret in geomorphic terms, recent studies of short-period seismic signals generated by mass movements provide some guidance. They lead us to suspect that the observed signal may have resulted from a complex breakaway sequence that merged into one apparent failure event, with possibly free-fall episodes, followed by a short runout that was abruptly stopped by topographic obstacles. Analysis of the seismic energy of the signal filtered between $3-10 \mathrm{~Hz}$ recorded at the JCW station gives a rough estimate of the volume of the second event, at around $15-30 \%$ of the total mobilized volume, in agreement with that estimated from other observations. Based on this estimate and the volume inferred for the first landslide from long-period seismic wave inversion, we deduce the total debris volume mobilized by the Oso-Steelhead events to be between $7 \times 10^{6}$ and $10 \times 10^{6} \mathrm{~m}^{3}$, consistent with estimates from ground observations and lidar mapping (Iverson et al., 2015). 


\section{Appendix A: Comparison with the results of Iversion et} al. (2015)

In a recent study, Iverson et al. (2015) presented a comprehensive investigation of the Oso landslide, including a seismological analysis of the force history of the landslide. Their seismological analysis, which is based on a methodology developed by Allstadt (2013), is different from the analysis presented here, and leads to significantly different results for the force history and inferred dynamics of the Oso landslide. In particular, while our results indicate a simple overall slide history, Iverson et al. (2015) concluded that the Oso landslide occurred as a two-stage failure, with the first stage ("interval 1" in their study) involving acceleration and deceleration of a coherent mass at the low end of the slope, which subsequently destabilized material above it, leading to a more energetic second stage. A second notable difference is that Iverson et al. (2015) determine a maximum force that is approximately one fifth of the maximum force obtained in our study.

Here we illustrate how the initial part of the force history determined by Iverson et al. (2015) is likely spurious and a consequence of the narrow frequency band used in their seismological data analysis. Similarly, we show that the small magnitude of the forces recovered in the Iverson et al. (2015) study is a second consequence of the details of their data analysis.

The method of Allstadt (2013) for recovering the history of forces acting on the Earth's surface is technically close to a time-domain deconvolution. If we denote the forces exerted on the Earth by the landslide motion by $F(t)$, the effects of the propagation through the Earth (the Green function) by $G(t)$, and the resulting ground displacement at the seismometer by $S(t)$, these functions are related by

$S(t)=F(t) * G(t)$,

where $*$ signifies convolution. Allstadt (2013) recovers the force history from observed ground motion $O(t)$ by solving an inverse problem for the time series $F(t)$ by minimization of the squared difference between $O(t)$ and the predicted $S(t)$. Ideally, this procedure can recover $F(t)$ without assumptions about the origin time of the landslide, or its time history. This is in contrast with the parameterized inversion method used in our analysis (Ekström and Stark, 2013), in which the force history is prescribed to have a finite duration, and the origin time is solved for in an iterative inversion.

Difficulties with a deconvolution approach arise when part of the landslide signal is buried in the background seismic noise, and only a band-passed version of $O(t)$ is matched in the inversion. The recovered force will then be a band-passed version of the true $F(t)$.

We simulated the analysis performed by Iverson et al. (2015) to investigate the effect of the narrow period band (30-60 s) used in their inversion. We first simulated the observed signal in the simplest way, by convolving our LFH

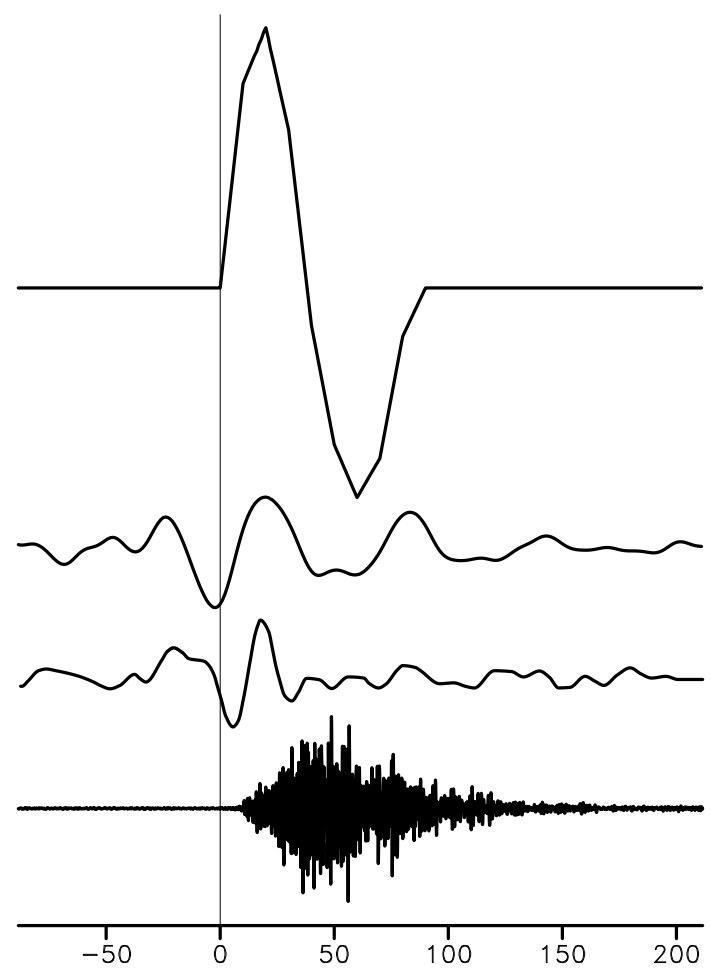

Figure A1. curve shows the N-S force history as determined in our analysis (cf. Fig. 4). Second curve from the top shows the output from our simulation of the effect of the method used by Iverson et al. (2015) on the recovery of the N-S force history. The third curve from the top shows the N-S force as determined in Iverson et al. (2015). The top three curves are plotted with the same vertical scale, and on the same time axis, with 0 corresponding to 17:37:10.5 (UT). The bottom trace shows the short period seismogram recorded at the closest station JCW, shifted earlier by $6.4 \mathrm{~s}$ to account for the propagation delay to the station.

with a band-pass filter with the parameters used by Iverson et al. (2015), and by taking the derivative to capture the fundamental relationship between forces acting on the Earth's surface, and the observed ground displacement at a distance (Lamb, 1904). We then fitted the filtered signal by minimizing the difference between it and a similarly filtered prediction by inverting for the time history $F(t)$. Because the problem is poorly posed after the signal has been band-pass filtered, we minimize the norm of $F(t)$ in the same way as Iverson et al. (2015) to stabilize the inversion.

Figure A1 illustrates the result of this simulation experiment for the $\mathrm{N}-\mathrm{S}$ component of the force. The top trace shows the force history determined in our study. The sinusoidal shape is typical of landslides, corresponding to a centre-of-mass acceleration followed by deceleration, with a duration of $\sim 80 \mathrm{~s}$. The second trace shows the output from the inversion that simulates the analysis of Iverson et al. (2015). The amplitude of the force is only $\sim 20 \%$ of the input force history, illustrating the distortion caused by the narrow band-pass filter and damped inversion. The second 


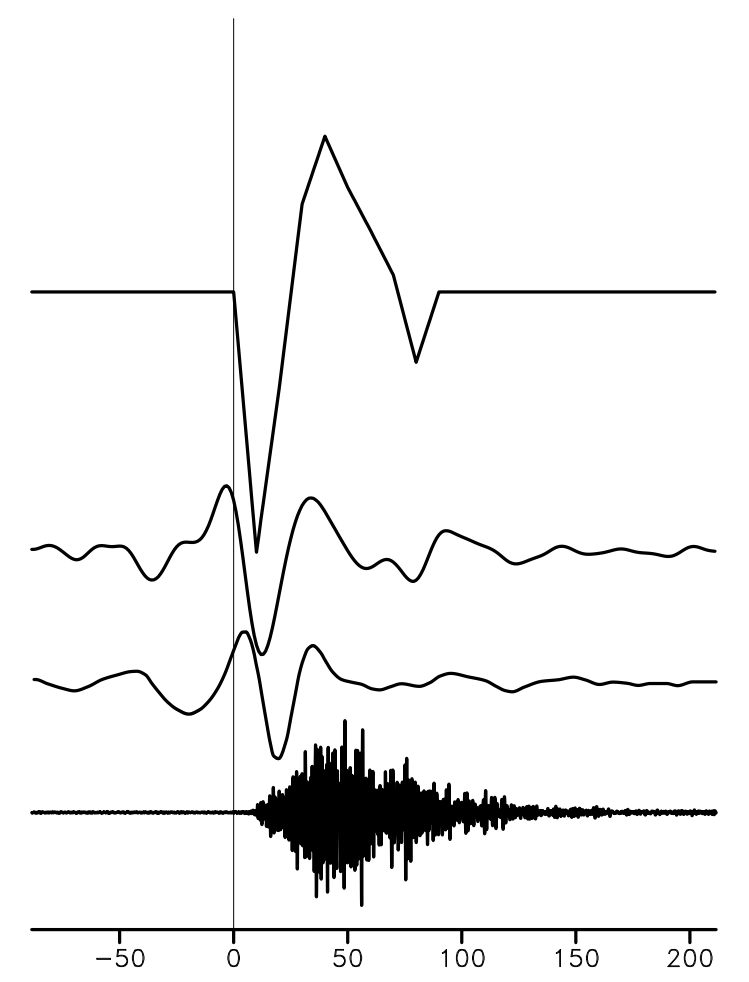

Figure A2. Same as Fig. A1, but showing the E-W force history.

trace also shows significant signal before the onset of the input force, reflecting that the deconvolution by inversion introduces acausal precursory signals, or Gibbs effects. The third trace shows the force history of Iverson et al. (2015), plotted on the same absolute time scale. The low amplitude of the force and the precursory signal are characteristics that closely resemble the acausal and attenuated output of our simulation. The results for the E-W and U-D components of the force are analogous as shown in Figs A2 and A3.

The similarities of the force histories of Iverson et al. (2015) and our results after simulating their analysis steps and using our best estimate of the true landslide force history are striking. We infer from this experiment that one key element of the seismological results presented in Iverson et al. (2015), the 40 s early sliding during "interval 1 " is a spurious result that is a consequence of the narrow band-pass filter used in the filtering and inversion of the seismograms. This inference is corroborated by examination of the short-period seismogram recorded at the station JCW at $11.5 \mathrm{~km}$ distance from the landslide. We follow Iverson et al. (2015) and shift the trace earlier by $6.4 \mathrm{~s}$ to account for a propagation delay before comparing the timing of the record with that of the inferred landslide forces. We find that the emergent JCW signal agrees very well with the onset of the landslide force as determined in this study. This is consistent with results from other well-recorded landslides (e.g. Hibert et al., 2014). The absence of earlier short-period signal at JCW further supports

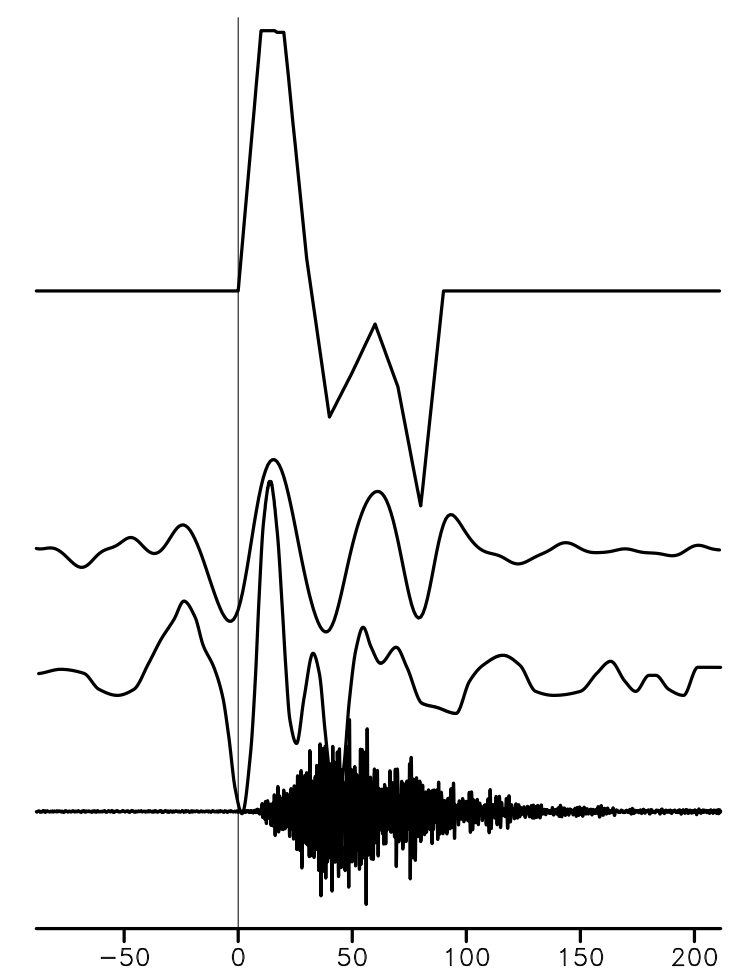

Figure A3. Same as Fig. A1, but showing the U-D force history.

our inference that the forces during "interval 1" discussed by Iverson et al. (2015) are spurious.

The experiment provides an explanation for the difference in the force magnitude. The forces determined by Iverson et al. (2015) are small and not consistent with the centre-ofmass movement observed. On the other hand, we find good agreement between our combined mass estimate and trajectory, obtained by integration of our force history, and the observed and simulated mass transport reported by Iverson et al. (2015). 
Acknowledgements. This work was supported by the US National Science Foundation Division of Earth Sciences and the Geomorphology and Land-use Dynamics/Geophysics programs under awards 1227083 and 1148176, and the US National Science Foundation Division of Civil, Mechanical and Manufacturing Innovation and the Hazards SEES program under award 1331499. We thank the operators of the seismic networks for collecting the data used in this study, and the IRIS Data Management System for providing easy access to the data.

Edited by: F. Guzzetti

Reviewed by: three anonymous referees

\section{References}

Allstadt, K.: Extracting source characteristics and dynamics of the August 2010 Mount Meager landslide from broadband seismograms, J. Geophys. Res., 118, 1472-1490, doi:10.1002/jgrf.20110, 2013.

Brodsky, E. E., Gordeev, E., and Kanamori, H.: Landslide basal friction as measured by seismic waves, Geophys. Res. Lett., 30, 2236, doi:10.1029/2003GL018485, 2003.

Dammeier, F., Moore, J. R., Haslinger, F., and Loew, S.: Characterization of alpine rockslides using statistical analysis of seismic signals, J. Geophys. Res., 116, F04024, doi:10.1029/2011JF002037, 2011.

Deparis, J., Jongmans, D., Cotton, F., Baillet, L., Thouvenot, F., and Hantz, D.: Analysis of rock-fall and rock-fall avalanche seismograms in the French Alps, Bull. Seismol. Soc. Am., 98, 17811796, doi:10.1785/0120070082, 2008.

Dragovich, J., Stanton, B., Lingley Jr., W., Griesel, G., and Polenz, M.: Geologic Map of the Oso 7.5-Minute Quadrangle, Skagit and Snohomish Counties, Washington: Washington Division of Geology and Earth Resources Open-File Report 11, Washington Division of Geology and Earth Resources, Washington, 2003.

Ekström, G.: A global model of Love and Rayleigh surface wave dispersion and anisotropy, 25-250s, Geophys. J. Int., 187, 16681686, doi:10.1111/j.1365-246X.2011.05225.x, 2011.

Ekström, G. and Stark, C. P.: Simple scaling of catastrophic landslide dynamics, Science, 339, 1416-1419, doi:10.1126/science.1232887, 2013.

Favreau, P., Mangeney, A., Lucas, A., Crosta, G., and Bouchut, F.: Numerical modeling of landquakes, Geophys. Res. Lett., 37, L15305, doi:10.1029/2010GL043512, 2010.

Fukao, Y.: Single-force representation of earthquakes due to landslides or the collapse of caverns, Geophys. J. Int., 122, 243-248, doi:10.1111/j.1365-246X.1995.tb03551.x, 1995.
Hibert, C., Mangeney, A., Grandjean, G., and Shapiro, N. M.: Slope instabilities in Dolomieu crater, Réunion Island: From seismic signals to rockfall characteristics, J. Geophys. Res., 116, F04032, doi:10.1029/2011JF002038, 2011.

Hibert, C., Ekström, G., and Stark, C. P.: Dynamics of the Bingham Canyon Mine landslides from seismic signal analysis, Geophys. Res. Lett., 41, 4535-4541, doi:10.1002/2014GL060592, 2014.

Huang, R.-Q.: Large-scale landslides and their sliding mechanisms in China since the 20th century, Chinese J. Rock Mech. Eng., 26, 433-454, 2007.

Iverson, R. M., George, D. L., Allstadt, K., Reid, M. E., Collins, B. D. Vallance, J. W., Schilling, S. P., Godt, J. W., Cannon, C. M., Magirl, C. S., Baum, R. L., Coe, J. A., Schulz, W. H., and Bower, J. B.: Landslide mobility and hazards: implications of the 2014 Oso disaster, Earth Planet. Sc. Lett., 412, 197-208, 2015.

Kanamori, H. and Given, J. W.: Analysis of long-period seismic waves excited by the May 18, 1980, eruption of Mount St. Helens - A terrestrial monopole?, J. Geophys. Res., 87, 5422-5432, doi:10.1029/JB087iB07p05422, 1982.

Keaton, J. R., Wartman, J., Anderson, S., Benoît, J., deLaChapelle, J., Gilbert, R., and Montgomery, D. R.: The 22 March 2014 Oso Landslide, Snohomish County, Washington, GEER report, NSF Geotechnical Extreme Events Reconnaissance, http://www. geerassociation.org/GEER_Post_EQ_Reports/Oso_WA_2014/, last access: June 2015, 172 pp., 2014.

Lamb, H.: On the propagation of tremors over the surface of an elastic solid, Philos. T. Roy. Soc. Lond. A, 203, 1-42, doi:10.1098/rsta.1904.0013, 1904.

Moretti, L., Mangeney, A., Capdeville, Y., Stutzmann, E., Huggel, C., Schneider, D., and Bouchut, F.: Numerical modeling of the Mount Steller landslide flow history and of the generated long period seismic waves, Geophys. Res. Lett., 39, L16402, doi:10.1029/2012GL052511, 2012.

Schneider, D., Bartelt, P., Caplan-Auerbach, J., Christen, M., Huggel, C., and McArdell, B. W.: Insights into rock-ice avalanche dynamics by combined analysis of seismic recordings and a numerical avalanche model, J. Geophys. Res., 115, F04026, doi:10.1029/2010JF001734, 2010.

Suriñach, E., Vilajosana, I., Khazaradze, G., Biescas, B., Furdada, G., and Vilaplana, J. M.: Seismic detection and characterization of landslides and other mass movements, Nat. Hazards Earth Syst. Sci., 5, 791-798, doi:10.5194/nhess-5-791-2005, 2005.

Vilajosana, I., Suriñach, E., Abellán, A., Khazaradze, G., Garcia, D., and Llosa, J.: Rockfall induced seismic signals: case study in Montserrat, Catalonia, Nat. Hazards Earth Syst. Sci., 8, 805-812, doi:10.5194/nhess-8-805-2008, 2008.

Yamada, M., Kumagai, H., Matsushi, Y., and Matsuzawa, T.: Dynamic landslide processes revealed by broadband seismic records, Geophys. Res. Lett., 40, 2998-3002, doi:10.1002/grl.50437, 2013. 